\title{
Evaluation of Uniformity of Bamboo Bundle Veneer and Bamboo Bundle Laminated Veneer Lumber (BLVL)
}

\author{
Haiying Zhou ${ }^{1}\left(\mathbb{D}\right.$, Xin Wei $^{1}$, Lee M. Smith ${ }^{2}$, Ge Wang ${ }^{1}$ and Fuming Chen ${ }^{1, *}$ \\ 1 Key Laboratory of Bamboo and Rattan Science and Technology of the State Forestry Administration, \\ Department of Bio-Materials, International Centre for Bamboo and Rattan, Beijing 100102, China; \\ 15288423522@163.com (H.Z.); weixin199522@163.com (X.W.); wangge@icbr.ac.cn (G.W.) \\ 2 Mechanical and Energy Engineering, University of North Texas, Denton, TX 76203-1277, USA; \\ LeeSmith@my.unt.edu \\ * Correspondence: fuming@icbr.ac.cn; Tel.: +86-010-847-8743
}

Received: 3 September 2019; Accepted: 17 October 2019; Published: 19 October 2019

\begin{abstract}
The lack of an effective and practical quality control method for industrialized bamboo bundle veneers is the key restriction in the application of bamboo bundle composite materials in the field of construction. In this work, the density uniformity and mechanical properties of bamboo bundle veneers were systematically evaluated by the combination of light transmittance and mechanical stiffness. It was found that the number of broomings, dippings, and high-temperature heat treatments had different effects on the bamboo bundle veneers. On this basis, the uniformity of the density and mechanical properties of the bamboo scrimber (BS) that underwent hybrid paving, and the bamboo bundle laminated veneer lumber (BLVL), were analyzed. The results showed that the performance stability of bamboo bundle composites could be greatly improved by bamboo bundle veneer laminated paving. A large-scale quality evaluation system for bamboo bundle veneers was established in this work, and it provides conditions for the manufacture of bamboo bundle composites with stable and controllable performance.
\end{abstract}

Keywords: quality evaluation; woven; bamboo bundle veneer; light transmittance; mechanical stiffness; uniformity

\section{Introduction}

Bamboo scrimber (BS) is a bamboo-based composite material that is made from bamboo bundle or fiberized bamboo veneers that have been layered-up in parallel, glued, and hot-pressed or cold-pressed. BS possesses good durability, good mechanical strength, and a high density $\left(1.15 \mathrm{~g} / \mathrm{cm}^{3}\right.$ or more) [1-3]. It is widely used in outdoor flooring, landscaping, and structural applications [4-6]. At present, bamboo scrimber is manufactured either by cold pressing or hot pressing, from bamboo bundle units or fiberized bamboo veneers that are dried, impregnated with adhesive, and manually paved according to the weighing method. The weighing method can easily cause uneven paving, which results in an uneven density, uneven stress, and other defects within the boards $[1,7,8]$. Currently, bamboo scrimber manufacturing requires high-pressure, high-density, and high-energy rough processing in order to ensure a good dimensional stability, glueing interface, and surface quality. In order to reduce energy consumption and improve the uniformity of bamboo scrimber manufacturing, Wang et al [7-11]. carried out a study on the processing of bamboo bundles from which bamboo bundle laminated veneer lumber (BLVL) was developed based on bamboo scrimber. The density of BLVL can be reduced to $1.05 \mathrm{~g} / \mathrm{cm}^{3}$, and its mechanical strength was comparable to the density of $1.25 \mathrm{~g} / \mathrm{cm}^{3}$ of bamboo scrimber made with hybrid pavement, which was a breakthrough in the quality control of bamboo 
scrimber [7-11]. The quality of the bamboo bundle units/bamboo bundle veneers had an important influence on the physical and mechanical properties of the bamboo scrimber. The uniformity of bamboo veneers is what determines the uniformity of both the density and mechanical properties of the BLVL. Effective quality evaluation of bamboo bundle veneers was a prerequisite for the manufacture of high-performance outdoor bamboo scrimber where the performance and structural design could be controlled.

The bamboo bundle veneer was generally manufactured by fine-brooming, and the wide-sized bamboo bundles were then sewn together [7,10-13]. Various studies on the types of fiber mesh connectors of the bamboo bundle veneers were performed, and they found that the bamboo bundle veneers with a cotton fiber mesh had the highest efficiency. The spacing of the fiber mesh had a direct influence on the quality of the bamboo bundle veneers, and it possessed better tensile properties at a spacing of $40 \mathrm{~cm}$. However, there were problems due to the sewing method used to prepare the bamboo bundle veneers. As bamboo bundles have a high hardness, the needles used to sew the fiber mesh to the bamboo were easily broken, which affected work efficiency. The low degree of automation and efficiency are the bottlenecks restricting the industrialized production of bamboo bundle veneers, which is why the process of bamboo bundle veneer is still in the research stage of development.

It is a well-recognized fact that the morphology and degree of brooming on the bamboo bundle affects the physical and mechanical properties of the bamboo bundle composites. The holistic quality evaluation of bamboo bundle veneers was of great significance for guiding the production of quality bamboo bundle composites that possess uniform properties. When subjected to different brooming times, the degree of separation for bamboo vascular bundles and parenchyma cells was different. As the bamboo bundles are glued, they have different amounts of water-soluble phenolic resin applied, which leads to variations in the physical and mechanical properties of the bamboo bundle units/bamboo bundle veneers $[6,11,14,15]$. In order to reduce mold and increase the dimensional stability of bamboo scrimber, bamboo bundles are often subjected to high-temperature treatment, which can destroy the chemical structure of bamboo and affect its lignin and hemicellulose [16-19]. The physical and mechanical properties of the bamboo bundle units/bamboo bundle veneers changed due to the accuracy of the processing [20-23], as well as the surface density of the bamboo bundle veneers. Studies on the width, number of broomings, shape of fiber, fineness of fiber, transmittance, angle of the crack, and cross-sectional area of the bamboo bundles have led to some guiding conclusions on bamboo bundle veneers $[1,2,6,24-27]$. However, these studies were quality evaluations of bamboo bundle units and the results were affected by various factors such as software selection, processing accuracy, and material differences. At present, there is no thorough research on the quality evaluation of bamboo bundle veneers. The lack of standardized bamboo bundle veneer processing technology and high-efficiency quality evaluation methods of bamboo bundle veneers are key restrictions preventing the improvement in quality, reduction in density, and improvement in production efficiency of bamboo scrimber, which could lead to the automation and continuous improvement of the bamboo scrimber industry.

In this study, narrow bamboo bundles with a width of about $2-3 \mathrm{~cm}$ were woven into a bamboo bundle veneer. This method of preparing the bamboo bundle veneer greatly improved the production efficiency of the bamboo bundle composites and can be facilitated in industrial applications. A real-time online evaluation system was used to evaluate the bamboo bundle veneers with light transmittance and mechanical stiffness as the main evaluation indexes, which can not only evaluate the uniformity of the bamboo veneers but also evaluate the mechanical properties of the bamboo veneers. This quality assessment standard for bamboo bundle veneers provides the basis for the manufacture of high-performance and special-purpose bamboo bundle composites in the future. A comparison of density uniformity and mechanical property uniformity between BLVL prepared by the lamination of bamboo bundle veneers and traditional bamboo scrimber with the hybrid paving was carried out. This study focused on the quality evaluation of bamboo bundle veneers in order to quantitatively characterize their quality and, thus, stabilize the performance of their final product of bamboo bundle veneer laminated composites. This stabilization of bamboo bundle veneers will allow the manufacture 
of high-performance bamboo bundle veneer laminated composites with controllable performance and structural design.

\section{Materials and Methods}

\subsection{Materials}

\subsubsection{Bamboo Bundle Veneers}

Moso bamboo (Phyllostachys pubescens [28,29]) that is 3-4 years old was harvested from Yong'an, Fujian Province in China. Bamboo strips $2-3 \mathrm{~cm}$ wide were obtained by splitting the bamboo tubes longitudinally by rolling and brooming them into bamboo bundles with a rolling machine. By controlling the number of broomings (one and two times), bamboo bundle units with different morphological features were obtained. Then, the broomed bamboo bundles were prepared into bamboo bundle veneers by using a weaving machine. To prepare bamboo bundle veneers, commercial cotton threads were purchased from Yongan City, Fujian Province, China and used to connect the bamboo bundles [30].

Cotton threads were selected to function as a connecting line that would hold the bamboo bundles together. Five lines of thread were arranged along the $1.9 \mathrm{~m}$ long bamboo bundle veneers. In order to avoid the bamboo bundle veneers loosening, the distance between the cotton threads and the edge of the bamboo bundle veneers was $15 \mathrm{~cm}$, and the threads were set $40 \mathrm{~cm}$ apart from each other across the length. The bamboo bundles were transversely woven into bamboo bundle veneers (Figure 1).

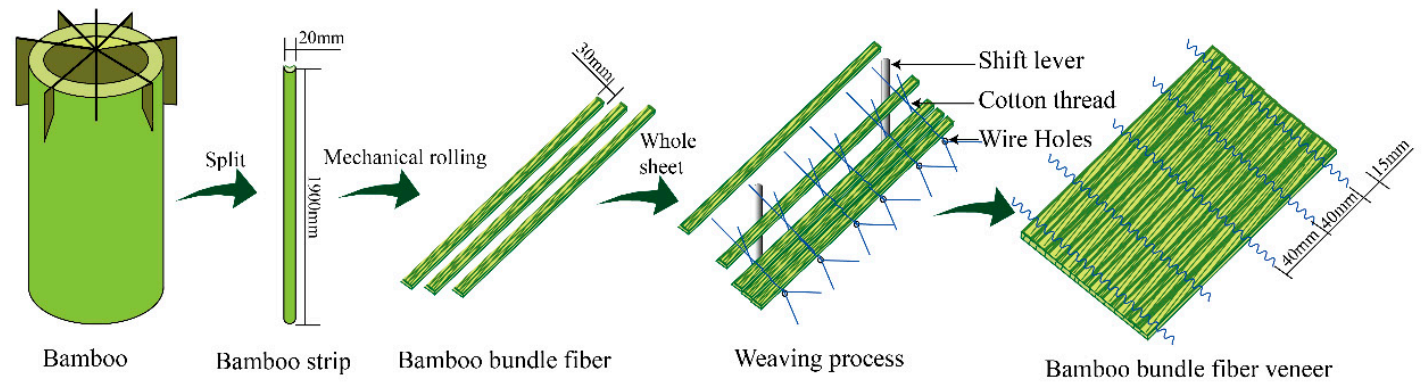

Figure 1. Schematic diagram of the weaving process of the bamboo bundle veneer.

According to industrial production methods, two different pressures of heat treatment were used on the bamboo bundles. A horizontal pressure vessel (Zhenghe Xiongfeng Boiler Manufacturing Co., Ltd., in Fujian, China) was used to apply a high-pressure heat treatment of 0.32-0.34 MPa at a temperature of $130-150^{\circ} \mathrm{C}$ for a time of $150 \mathrm{~min}$. The low-pressure heat treatment used a pressure of $0.10-0.12 \mathrm{MPa}$ at a temperature of $110-120^{\circ} \mathrm{C}$ for a period of time of $120 \mathrm{~min}$. After the thermal treatment, the moisture content (MC) was reconditioned to $10 \%$ in a drying room with an ambient temperature of $50-60{ }^{\circ} \mathrm{C}$.

Bamboo bundle veneers were impregnated with a phenolic resin (PF) that had a solid content of $18 \%$, which was diluted by a commercial water-soluble phenol formaldehyde resin with a solid content of $48.54 \%$ supplied by Taier Corporation, Guangdong, China. The bamboo bundle veneers were then dried to a MC between $8 \%$ and $12 \%$ in an ambient environment.

\subsubsection{Bamboo Scrimber (BS) and Bamboo Bundle Laminated Veneer Lumber (BLVL)}

A CARVER M-3895 hot press (Carver Inc, Wabash, IN, USA) was used to press the BS and BLVL at a temperature of $155^{\circ} \mathrm{C}$, for a press time of $30 \mathrm{~min}$ ( $1 \mathrm{~min}$ for press closing, $14 \mathrm{~min}$ of pressure at the target thickness, and 15 min for press opening). BS and BLVL were prepared by glue-drying the bamboo bundle unit hybrid paving and whole-sheet bamboo bundle laminated veneers, respectively. 
The dimensions and target density of the boards were $300 \mathrm{~mm}$ (length) $\times 150 \mathrm{~mm}$ (width) $\times 14 \mathrm{~mm}$ (thickness) and $1.0 \mathrm{~g} / \mathrm{cm}^{3}$, respectively.

\subsection{Methods}

\subsubsection{Quality Evaluation Method of Bamboo Bundle Veneers}

The light transmittance and stiffness were used as the evaluation indexes to quantitatively characterize the quality of bamboo bundle veneers.

\section{Light Transmittance Detection}

The uniformity of the brooming morphology used to make the bamboo bundle veneer was observed by the optical transmittance detection method, which uses a light generator to project light onto one side of the bamboo bundle veneer and an optical analyzer to collect the light transmittance on the other side. The uniformity of the brooming morphology was estimated by calculating the optical loss of the light passing through the bamboo bundle veneer (Figure 2).

$$
L=\frac{S}{S_{0}} \times 100 \%
$$

where $L$ is the light transmittance, in $\% ; S$ is the power of the actual optical signal received by the photodiode (PD), in $\mathrm{V} ; S_{0}$ is the power of the initial optical signal received by the photodiode (PD), in V.

Eight pairs of photodetectors were set-up according to the lateral width of the bamboo bundle veneer, which would pass between the photodetector pairs. The photodetector pairs consisted of two components, a light-emitting diode (LED) light emitter on the bottom below the bamboo bundle veneers and a photodiode that functions as an optical analyzer on the top. The LED flashes at a fixed frequency that only the photodiode (PD) recognizes as the optical signal. When the gap size of the bamboo bundle veneer changes, the intensity and duration of the optical signal received by PD will differ. Based on the characteristics of the optical signal received by the PD, the uniformity of the density of the whole bamboo bundle can be estimated.

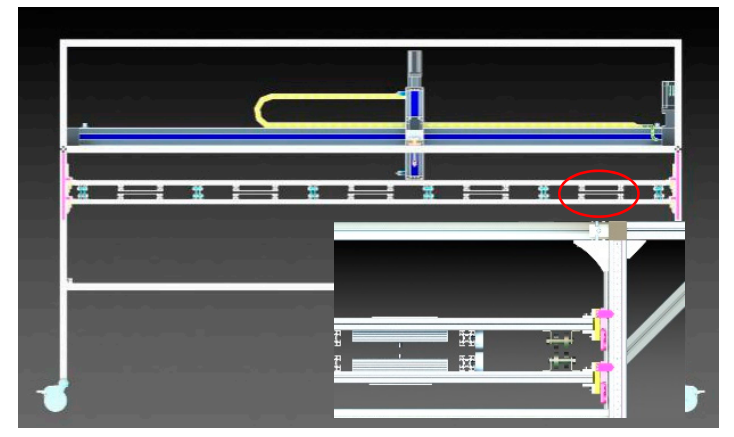

(a)

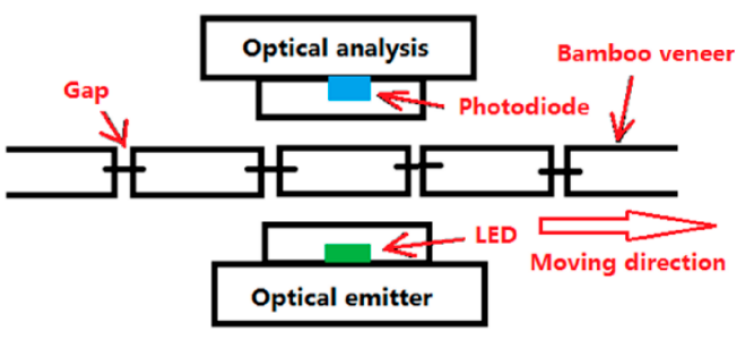

(b)

Figure 2. Test schematic diagram of the light transmittance. (a) Frame structure of evaluation equipment; (b) test schematic of light transmittance.

The spot size emitted by the light emitter was $5.0 \mathrm{~cm}$, which was twice the width of the bamboo bundle units. This method not only monitored the transmittance of the bamboo bundle itself, but also detected gaps between the bamboo bundle units. According to the width of the materials, the step length of the transmittance detection was $5.0 \mathrm{~cm}$. The maximum transmittance of each photodetector channel was recorded in each step, allowing the gap size and mechanical property uniformity of the bamboo bundle veneers to be monitored in real time. In order to avoid the influence of bamboo chips and other impurities on the light transmittance, the control system automatically reset to zero before the light transmittance detection of each bamboo bundle veneer. The actual light transmittance of the 
bamboo bundle veneer was calculatedbased on the light transmittance at the moment to ensure the accuracy of the test results.

\section{Mechanical Stiffness Detection}

The mechanical crimping method was used to characterize the mechanical properties of the bamboo bundle veneers. A certain pressure according to a requirement was applied to the set positions of the bamboo bundle veneer, and the displacement at the application site was measured. The ratio of force to displacement was used to determine the mechanical stiffness of the bamboo bundle veneers.

$$
M S=\frac{F}{D}
$$

where $M S$ is the mechanical stiffness $(\mathrm{N} / \mathrm{mm}) ; F$ is the force $(\mathrm{N})$; and $D$ is the displacement $(\mathrm{mm})$.

A push bar with a built-in pressure sensor was mounted on the bamboo bundle veneer conveyor and used to detect the pressure value. The accuracy of the mechanical sensor was determined by the accuracy of the stepper motors that record the displacement. According to the stepper motor reducer setting and lead parameters, the displacement of every step was $33.33 / 2000 \mathrm{~mm} / \mathrm{step}$, that is, the accuracy of the pressure sensor was $0.0167 \mathrm{~mm}$. The pressure sensor calculates the displacement of the bamboo bundle veneer due to the force applied (Figure 3). According to the preliminary test, if the set pressure was too high, the bamboo bundle veneer would break, and if the pressure was too low, the error would be too large. Therefore, an optimized pressure of $30 \mathrm{~N}$ was selected to test the mechanical stiffness of the bamboo bundle veneers.

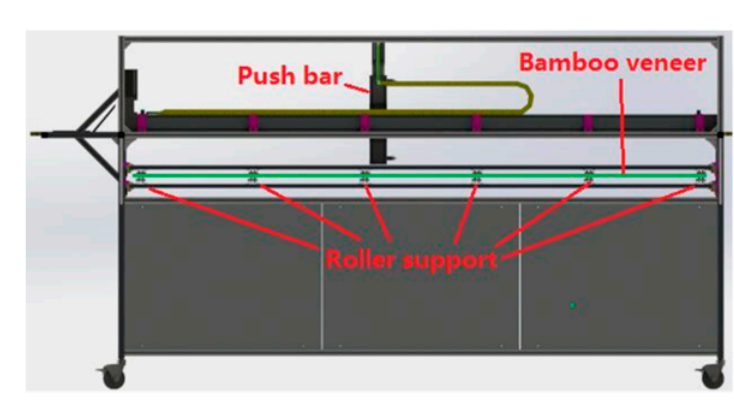

(a)

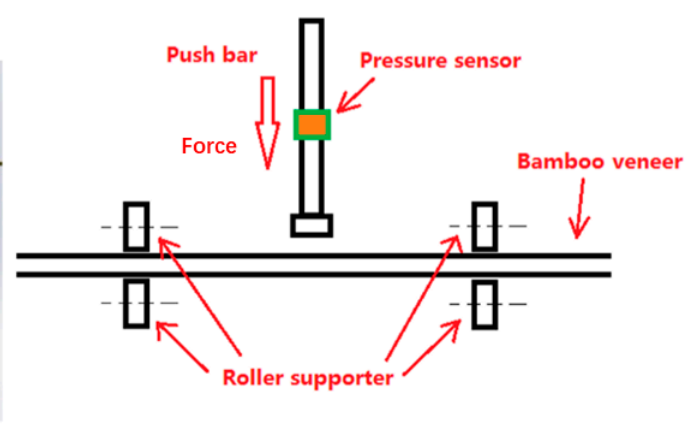

(b)

Figure 3. Test schematic diagram of the mechanical stiffness. (a) Frame structure of evaluation equipment; (b) test schematic of mechanical stiffness.

Four mechanical stiffness detection channels were set-up according to the veneer length. The deformation detection points were set in the middle of the support rollers, and the spacing between the neighboring support roller was adjustable. The shape and size of the plane indenter can be adjusted to suit different materials. The diameter of the indenter on the push bar was twice the width of a single bamboo bundle unit in order to detect the mechanical stiffness of the bamboo bundles and the gap between them. The mechanical stiffness and light transmittance detection were performed simultaneously on a conveyor. The bamboo bundle veneers were transferred by a conveyor along their width where the length of the veneers first passed through the photodetectors to measure the light transmittance and were then moved down the conveyor where they were subjected to mechanical stiffness testing. This method of detecting the light transmittance and mechanical stiffness helps to develop a uniformity test that ensures the quality of the bamboo bundle veneers being used (Figure 4): 


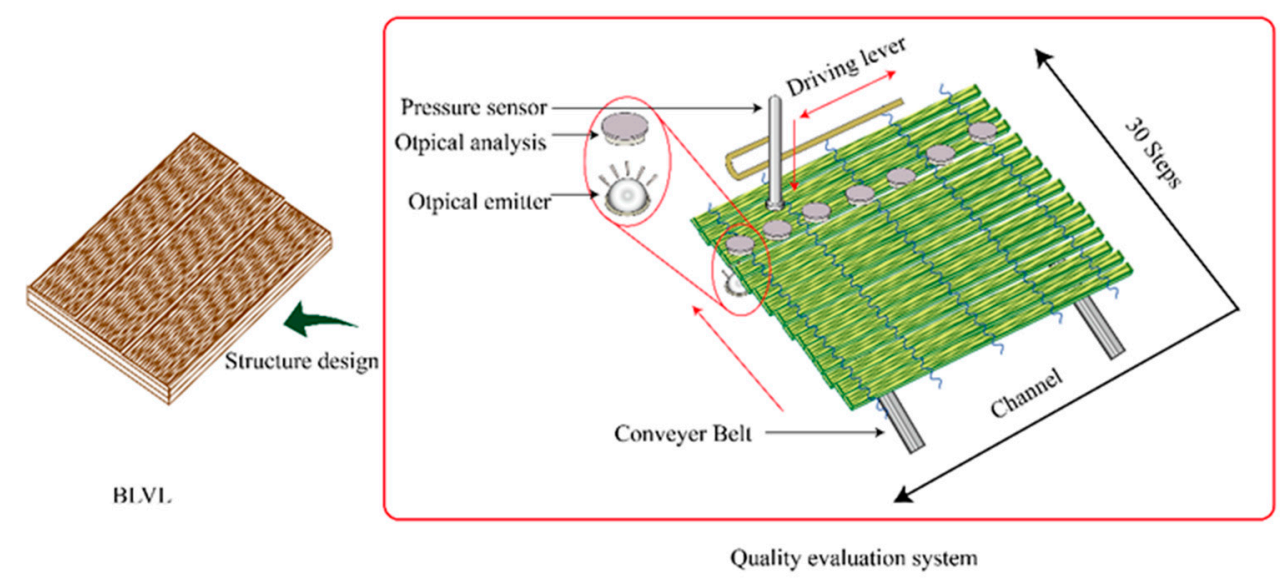

Figure 4. Test schematic diagram of the quality evaluation process of bamboo bundle veneer.

\subsubsection{Quality Stability Evaluation of BLVL and BS}

The performance stability of the boards was mainly embodied in the density uniformity and mechanical properties. In order to visually and clearly express the profile density distribution of each part of the whole board, 10 specimens measuring $50 \mathrm{~mm} \times 50 \mathrm{~mm} \times 14.0 \mathrm{~mm}$ were cut from the finished bamboo bundle laminated veneer lumber $(500 \mathrm{~mm} \times 300 \mathrm{~mm} \times 14.0 \mathrm{~mm})$ and had a profile density test performed on them, using a DENSE-LAB X-ray profile density tester from Hameln, Germany.

According to ASTM standard D1037-06a (ASTM 2006), modulus of rupture (MOR) and modulus of elasticity (MOE) of BLVL and BS were respectively determined. Three boards for both BS and BLVL were pressed and 24 test specimens measuring $300 \mathrm{~mm} \times 20 \mathrm{~mm} \times 14 \mathrm{~mm}$ were cut from them. Twelve test repetitions were performed for both the MOR and MOE testing.

\section{Results}

\subsection{Quality Evaluation and Analysis of Bamboo Bundle Veneers}

The light transmittance and mechanical stiffness data of the bamboo bundle veneers detected by the quality evaluation equipment were processed using the Origin software to obtain 3D empirical models of their distribution (Figure 5). The figures show the light transmittance and mechanical stiffness in the full-scale bamboo bundle veneers, and they reflect the density uniformity and mechanical properties of the bamboo bundle veneers.

In order to test the accuracy of the light transmittance and mechanical stiffness, a comparison of the bamboo bundle veneer with the bamboo mat was performed in order to determine the relative quality of uniformity. It was found that the light transmittance of the bamboo mat was less than that of the bamboo bundle veneer, and the transition was smoother in the full-scale range, indicating that the density uniformity of the bamboo mat was much higher than that of the bamboo bundle veneer. However, the mechanical stiffness of the bamboo mat was much smaller than that of the bamboo bundle veneer, but its uniformity was higher than that of the bamboo bundle veneer. The quality evaluation method can effectively evaluate and classify bamboo bundle veneers. 


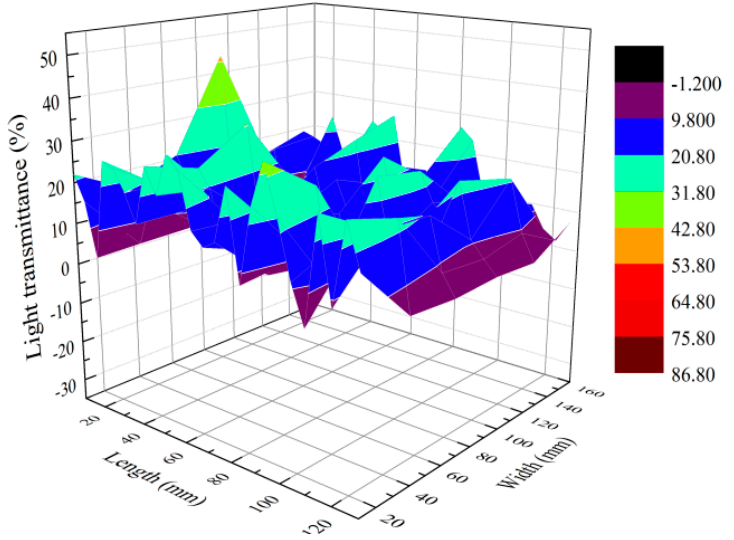

(a)

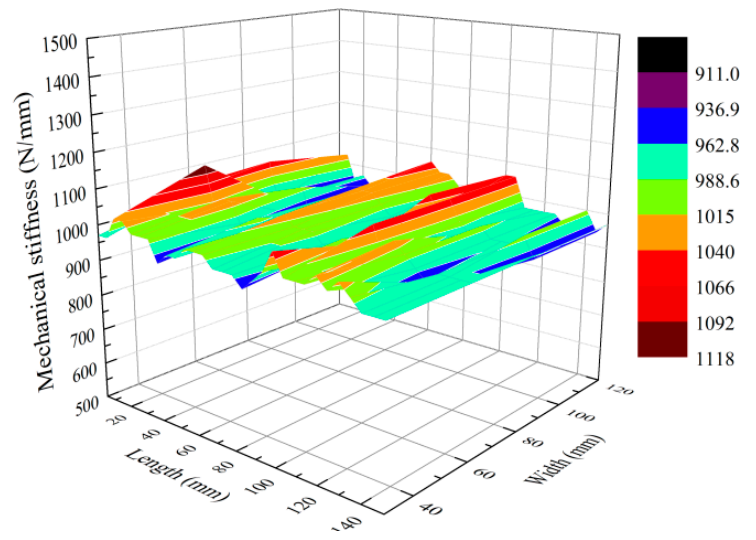

(c)

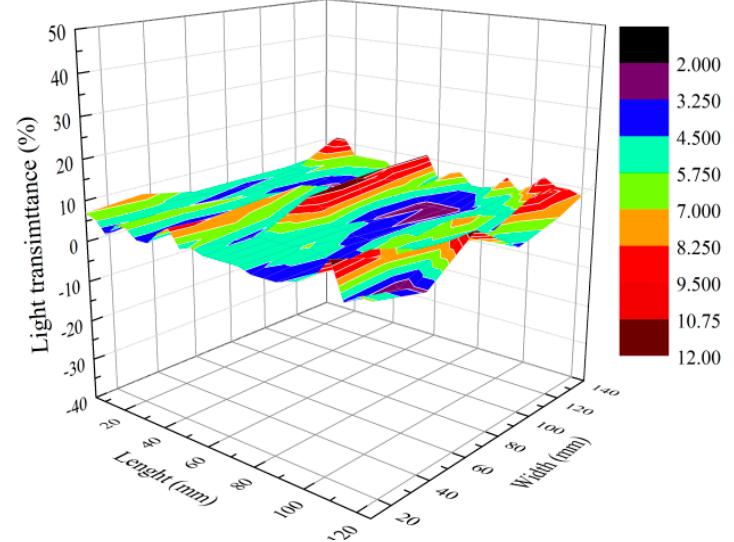

(b)

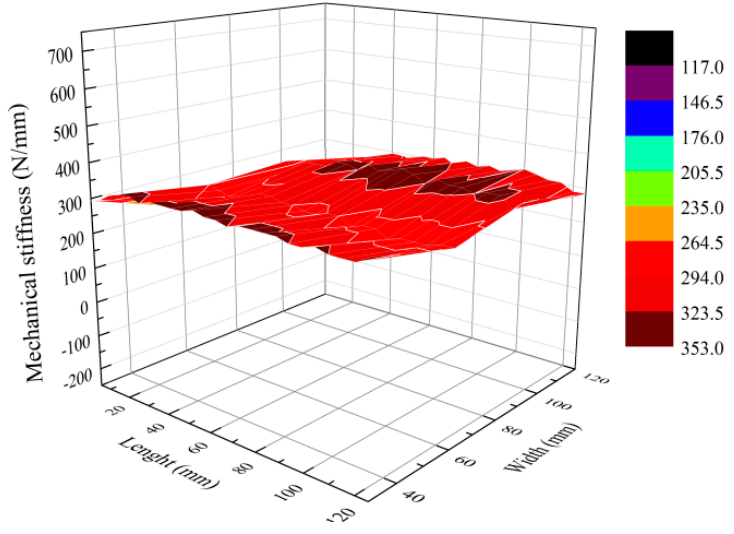

(d)

Figure 5. Light transmittance and mechanical stiffness of bamboo bundle veneer and bamboo mat. (a) 3D model diagram of light transmittance of bamboo bundle veneer; (b) 3D model diagram of light transmittance of bamboo mat; (c) 3D model diagram of mechanical stiffness of bamboo bundle veneer;

(d) 3D model diagram of mechanical stiffness of bamboo mat.

\subsection{Influence of the Degree of Brooming and Glue on the Quality of Bamboo Bundle Veneers}

The morphology of the bamboo bundle units had a direct relationship with the physical and mechanical properties of the bamboo-based boards they were used to make. The different degree of brooming and dipping also affected the physical and mechanical properties of the bamboo bundle veneers. Figure 6 shows the light transmittance of the bamboo bundle veneers with different brooming times before and after being dipped (the bamboo bundle veneer that underwent brooming once and twice is abbreviated as $S$ and $D$, respectively, while that after being glued is abbreviated as S-G and $D-G$, respectively). The degree of fiber bundle separation of the bamboo bundle unit could be changed by controlling the number of broomings, which had an effect on the light transmittance of the bamboo bundle veneers. As the proportions of parenchyma cells differ across the cross-section of bamboo, when it is processed, it can cause the mechanical stiffness of the bamboo bundles to vary. It was obvious that the light transmittance of the bamboo bundle veneers after one brooming was greater than that of the bamboo bundle veneers that underwent two broomings, and the dipping reduced the light transmittance of the bamboo bundle veneers. The end face of the bamboo bundle unit after one brooming was still compressed but had irregular cracks, and the fiber bundles were tightly grouped but not separated. After two broomings, the bamboo fiber bundles had smaller diameters and were intermittently connected to each other in a fine and uniform shape. Therefore, the light transmittance was lowered and the uniformity increased. The glued bamboo bundle veneers had a smaller light 
transmittance because the glue and dryness cause the bamboo bundles to contract laterally so that the gaps between the bamboo bundles were reduced. The light transmittance of the bamboo bundle veneers that had been broomed twice was lower than that which had undergone one brooming. The greater number of broomings also increased the uniformity of the bamboo bundles, which, in turn, helped to reduce the light transmittance.

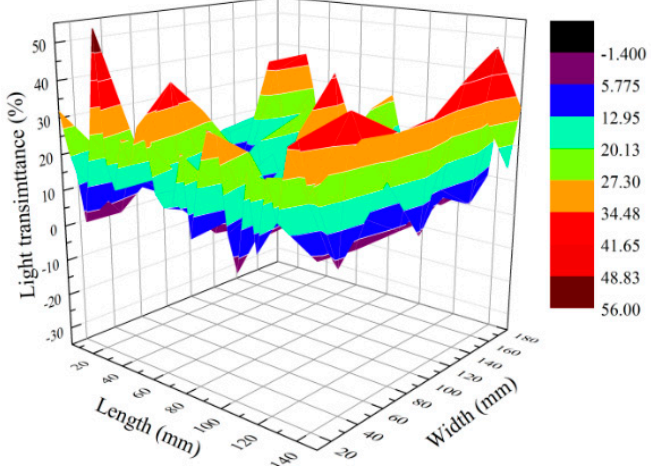

(a)

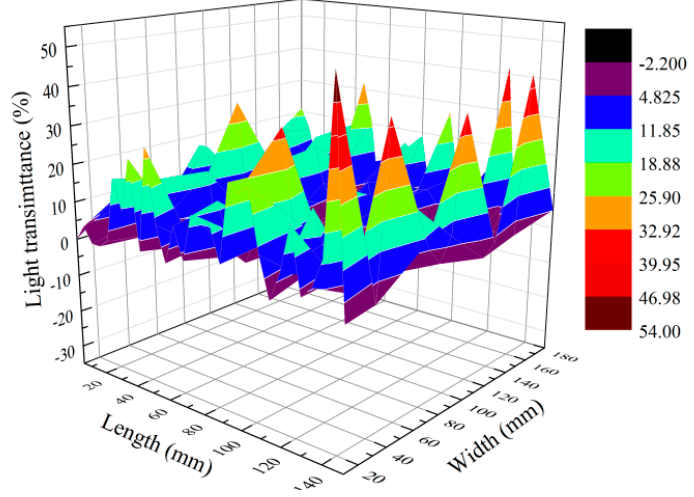

(c)

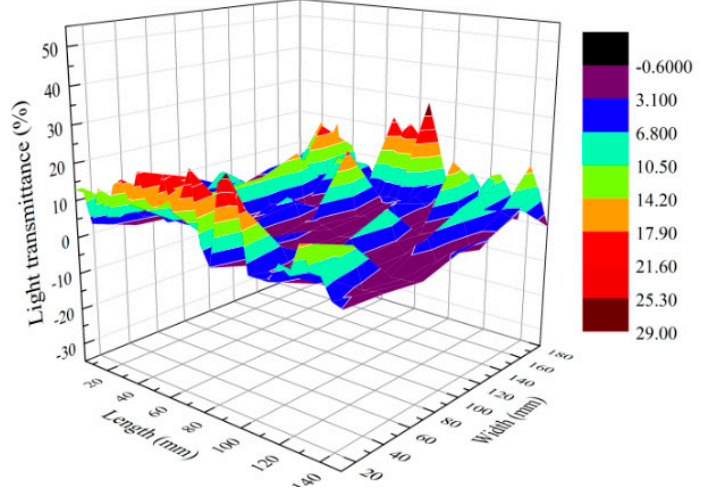

(b)

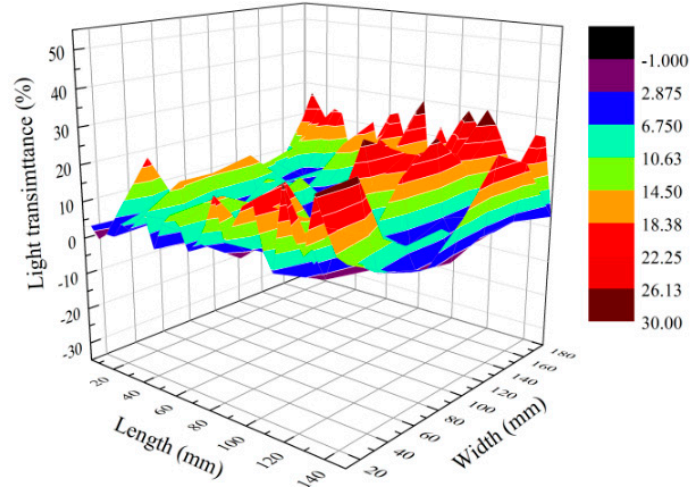

(d)

Figure 6. Comparison of light transmittance of bamboo bundle veneers before and after being dipped. (a) 3D model diagram of light transmittance of bamboo bundle veneers that underwent brooming once;

(b) 3D model diagram of light transmittance bamboo bundle veneers that underwent brooming twice;

(c) 3D model diagram of light transmittance of bamboo bundle veneers that underwent brooming once after being dipped; (d) 3D model diagram of light transmittance of bamboo bundle veneers that underwent brooming twice after being dipped.

Comparing the mechanical stiffness of the bamboo bundle veneers with different numbers of broomings, it was found that the mechanical stiffness curves of the bamboo bundle veneers fluctuated up and down between 800 and $1400 \mathrm{~N} / \mathrm{mm}$ (Figure 7). However, the mechanical stiffness of the bamboo bundle veneers broomed once was significantly higher than that of the bamboo bundle veneers broomed twice. As the two broomings processed, it led to a greater separation of the bamboo fiber bundles, causing more breaking in the fibers and stripping along the parenchyma cells. This breaking in the fibers and damage to the cells reduced the mechanical stiffness of the bamboo bundle veneers. The mechanical stiffness of bamboo bundle veneers increased after impregnation with resin. The flowing thermosetting phenolic resin (PF) was applied to the veneers by dipping it where it adhered to the surface and infiltrated into the gaps and cell gaps of the bamboo bundles. After being dipped, the veneers were subjected to drying at a temperature of $50-60{ }^{\circ} \mathrm{C}$. The PF was in a solid state on the surface and inside of the bamboo bundle veneers, granting the veneers flexibility, which increased the hardness and mechanical stiffness of the bamboo bundle veneers. 


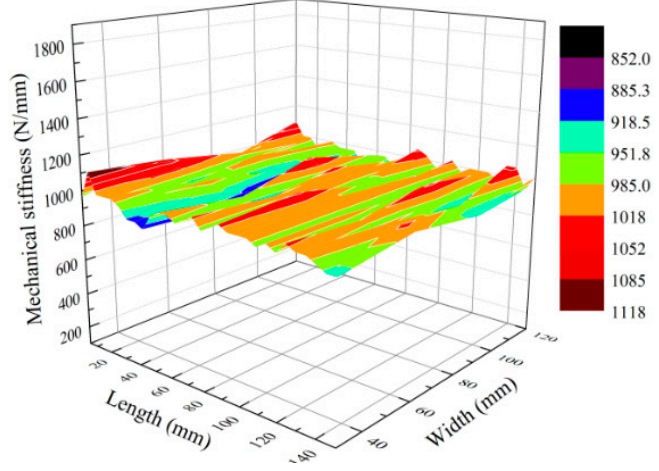

(a)

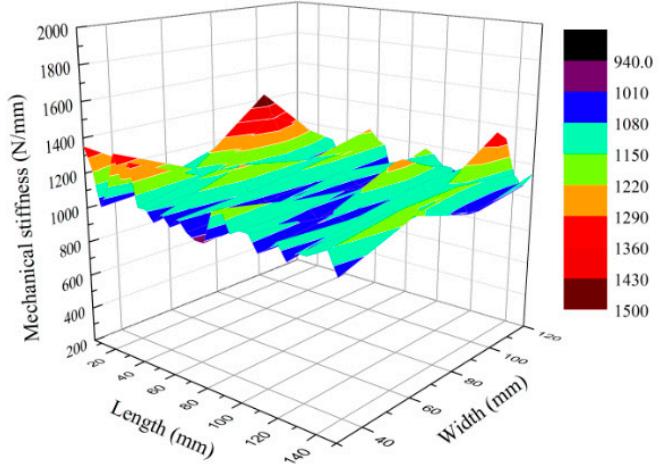

(c)

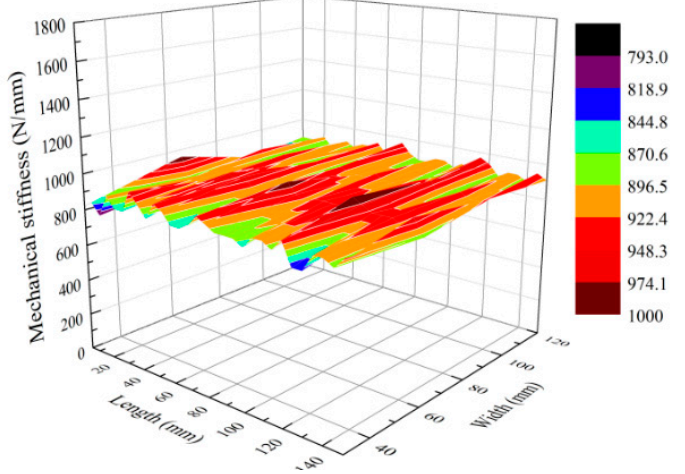

(b)

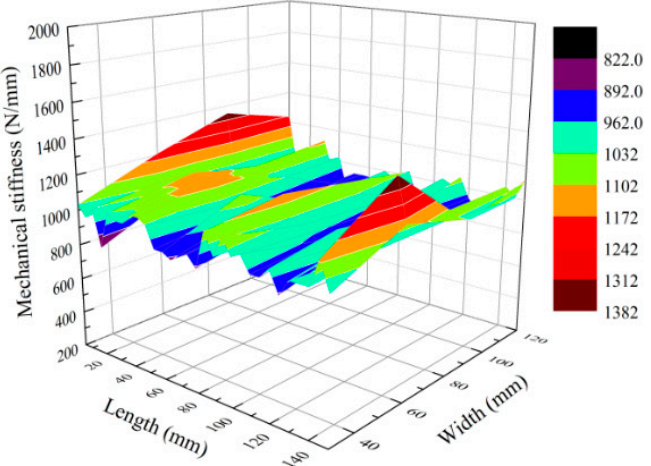

(d)

Figure 7. Comparison of mechanical stiffness of bamboo bundle veneers with different brooming times before and after being dipped. (a) 3D model diagram of mechanical stiffness of bamboo bundle veneers that underwent brooming once; (b) 3D model diagram of mechanical stiffness of bamboo bundle veneers that underwent brooming twice; (c) 3D model diagram of mechanical stiffness of bamboo bundle veneers that underwent brooming once after being dipped; (d) 3D model diagram of mechanical stiffness of bamboo bundle veneers that underwent brooming twice after being dipped.

The average value of the light transmittance and mechanical stiffness was affected by the number of broomings; to understand this effect, interactions between brooming, gluing, and drying of the bamboo bundle veneers were analyzed (Figure 8). The light transmittance and mechanical stiffness of the bamboo bundle veneers that underwent one brooming were $167.23 \%$ and $8.32 \%$ higher than those of the bamboo bundle veneers broomed twice, respectively. After being dipped, the mechanical stiffness of the bamboo bundle veneers with one brooming increased by $13.77 \%$ and the light transmittance decreased by $50.95 \%$. The mechanical stiffness of the bamboo bundle veneers that were broomed twice increased by $10.99 \%$, but the light transmittance increased by $72.33 \%$. Due to being subjected to two brooming treatments, the separated bamboo fibers were very loose and uniform. Once dried, the fiber bundles shrank, causing the gaps between adjacent fiber bundles to increase, which led to an increase in light transmittance. The separation of the bamboo bundle fibers after one brooming was very low, so once they dried, the shrinkage in the fiber occurred to the entire bamboo bundle, which contributed to the reduction of light transmittance. 


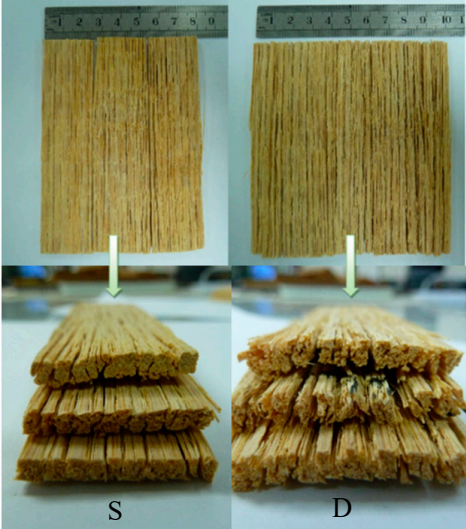

(a)

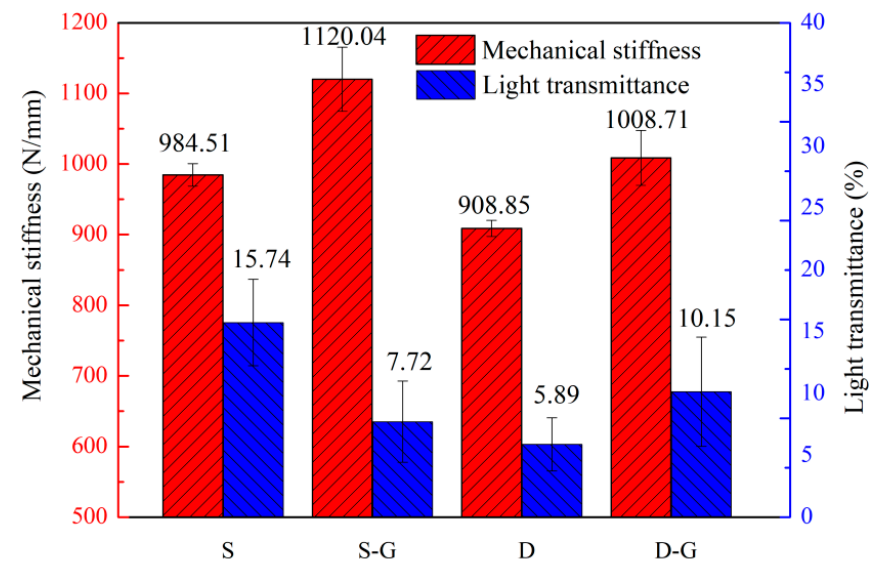

(b)

Figure 8. Average value of light transmittance and mechanical stiffness of bamboo bundle veneer. (a) Topography of bamboo bundle veneer with different numbers of broomings; (b) average value of light transmittance and mechanical stiffness of bamboo bundle veneer with different brooming times before and after being dipped. The bamboo bundle veneer that underwent brooming once and twice is abbreviated as S and D, respectively, while that after being glued is abbreviated as S-G and D-G, respectively.

\subsection{Effect of Heat Treatment on the Quality of Bamboo Bundle Veneers}

During production, bamboo bundles always undergo heat treatment in order to reduce mold and size changes of BS. This high-temperature heat treatment can destroy the chemical structure of the bamboo by removing lignin and hemicellulose from the bamboo. The impact of heat treatment under different pressures on the light transmittance and mechanical stiffness of the bamboo bundle veneers was studied and compared to the veneers that had not been heat-treated (Figure 9). It can be seen that the light transmittance and mechanical stiffness of the bamboo bundle veneers before and after heat treatment were relatively uniform. The heat treatment at lower pressure had little effect on the light transmittance and stiffness of the bamboo veneers, but the heat treatment at higher pressure had an influence on the transmittance and mechanical stiffness of the bamboo veneers. The influence on the mechanical stiffness could be due to the bamboo becoming plasticized after high-temperature heat treatment, which results in the reorganization of the cellulose polymer components [30] and partial crystallization of amorphous cellulose [31] that would cause an increase in the elastic modulus (MOE) [32].

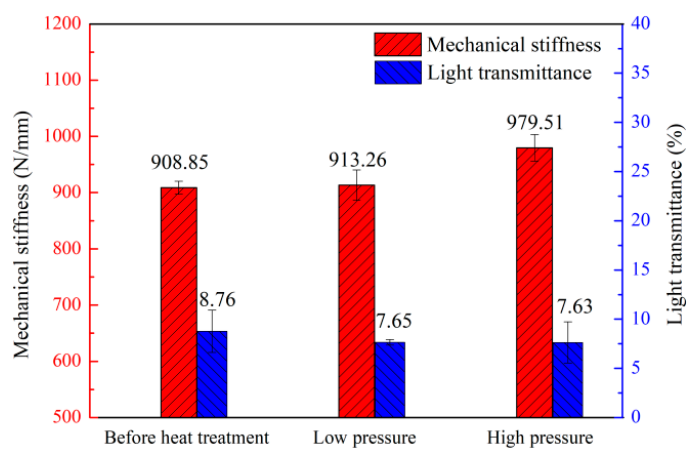

(a)

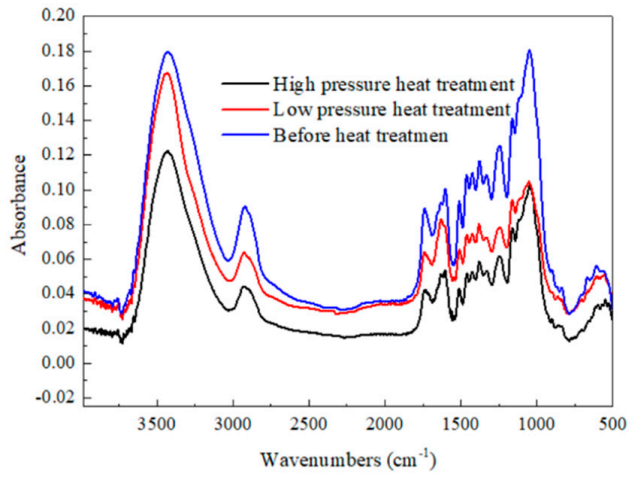

(b)

Figure 9. Light transmittance and mechanical stiffness of the bamboo bundle veneers that underwent heat treatment. (a) Average value of light transmittance and mechanical stiffness; (b) Fourier transform infrared spectroscopy (FT-IR) spectra of the bamboo bundle veneers before and after heat treatment. 


\subsection{The Density and Mechanical Uniformity of Traditional BS and Novel BLVL}

The quality of the bamboo bundle veneers was closely related to the physical and mechanical properties of the bamboo bundle fibers. To understand the relationship between the fibers and veneers, the density and mechanical properties of BLVL prepared by laminated bamboo bundle veneers and BS with hybrid paving were compared and analyzed (Figure 10). The variable density profile curves (VDP) of BS and BLVL fluctuated across their cross-section with the VDP of traditional BS (Figure 10a) having large dispersed fluctuations. The coefficient of variation (COV) of the average density, maximum density on the edges of the board, and minimum density were larger in BS than in BLVL. The COV of the maximum density was especially larger in BS than in BLVL, with the left and the right being 2.79 and 7.15 times those of BLVL, respectively (Table 1). The profile density curves of the BLVL were relatively flat (Figure 10c), and the COVs were below $4 \%$ (Table 1), indicating that the uniformity of the bamboo bundle veneers had greatly improved the density uniformity of the BLVL.

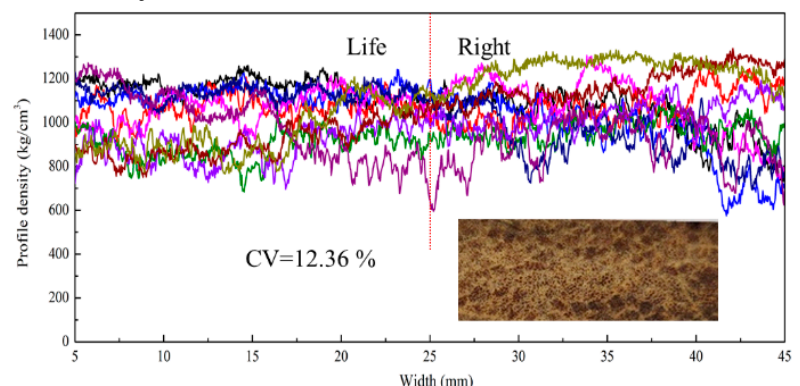

(a)

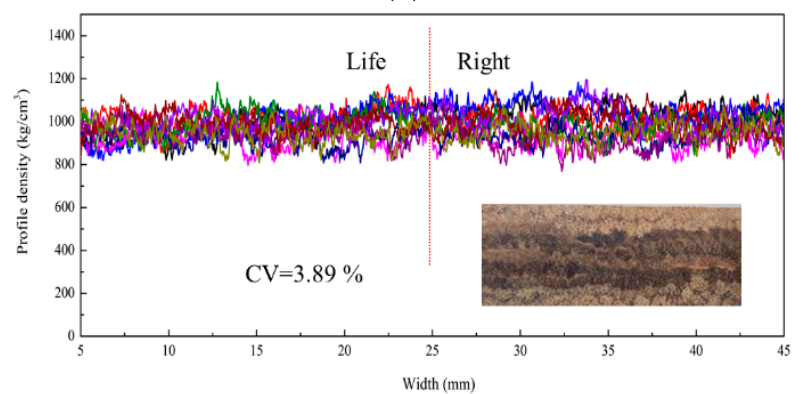

(c)

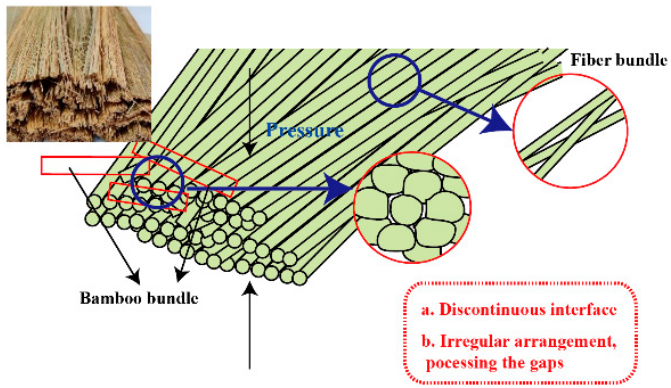

(b)

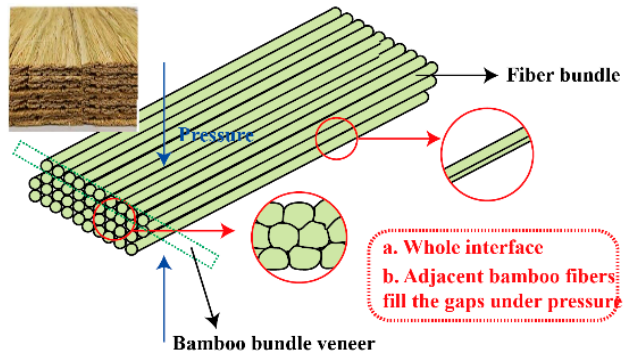

(d)

Figure 10. Profile density curves in width of bamboo scrimber (BS) and bamboo bundle laminated veneer lumber (BLVL). (a) Profile density curves in width and bond mechanism of BS; (b) fiber bonding mechanism of BS; (c) profile density curves in width and bond mechanism of BLVL; (d) fiber bonding mechanism of BLVL.

Table 1. Profile density values and mechanical properties of BS and BLVL.

\begin{tabular}{|c|c|c|c|c|c|c|}
\hline Types & $\begin{array}{l}\text { Average } \\
\text { Density } \\
\left(\mathrm{g} / \mathrm{cm}^{3}\right)\end{array}$ & $\begin{array}{c}\text { Maximum } \\
\text { Density on } \\
\text { the Left } \\
\left(\mathrm{g} / \mathrm{cm}^{3}\right)\end{array}$ & $\begin{array}{c}\text { Maximum } \\
\text { Density on } \\
\text { the Right } \\
\left(\mathrm{g} / \mathrm{cm}^{3}\right)\end{array}$ & $\begin{array}{l}\text { Minimum } \\
\text { Density } \\
\left(\mathrm{g} / \mathrm{cm}^{3}\right)\end{array}$ & $\begin{array}{l}\text { MOR } \\
(\mathrm{MPa})\end{array}$ & $\begin{array}{l}\text { MOE } \\
(\mathrm{GPa})\end{array}$ \\
\hline BS & $\begin{array}{c}1.02 \\
(12.36)\end{array}$ & $\begin{array}{c}1.04 \\
(10.16)\end{array}$ & $\begin{array}{c}1.01 \\
(19.53)\end{array}$ & $\begin{array}{c}0.66 \\
(9.90)\end{array}$ & $\begin{array}{l}104.57 \\
(26.68)\end{array}$ & $\begin{array}{c}12.57 \\
(39.71)\end{array}$ \\
\hline BLVL & $\begin{array}{c}0.98 \\
(3.89)\end{array}$ & $\begin{array}{c}1.00 \\
(3.64)\end{array}$ & $\begin{array}{c}1.03 \\
(2.73)\end{array}$ & $\begin{array}{c}0.81 \\
(2.71)\end{array}$ & $\begin{array}{l}121.31 \\
(7.90)\end{array}$ & $\begin{array}{c}15.83 \\
(10.79)\end{array}$ \\
\hline
\end{tabular}

Note: The values in the table are the average of 10 samples, and the coefficient of variation in ( ), $\%$. 
The mechanical properties of BLVL were significantly better than those of BS. In order to objectively compare the mechanical properties of BS and BLVL at the same density, the MOR and MOE were divided by the density to obtain the specific MOR and the specific MOE. It was found that the specific MOR and MOE of BLVL were $19.36 \%$ and $29.64 \%$ higher than those of BS, respectively (Figure 11). The COVs of MOR and MOE for BLVL were below $11 \%$, which was significantly lower than those for BS (COV $>20 \%$ ). This would indicate that the process of using bamboo bundles to produce bamboo bundle veneers with a relatively uniform fiber arrangement can improve the density and mechanical property uniformity of the bamboo bundle fiber composites. The bamboo fibers were arranged in the same direction, effectively increasing the specific surface area and having an improved adhesive interface (Figure 10b). However, in the hybrid pavement, the bamboo fibers were arranged at a certain angle, resulting in a decrease in the contact area between the fibers and a discontinuous bonding interface (Figure 10d). The thickness of the bamboo bundles was uneven, resulting in a large deviation in the overall density of the BS so that the mechanical properties of the BLVL were higher than those of BS, and the performance stability of BLVL was also higher than that of BS. The density and production cost of bamboo bundle fiber composites could be reduced by laminated bamboo bundle veneers, and it could create more economic value to them.

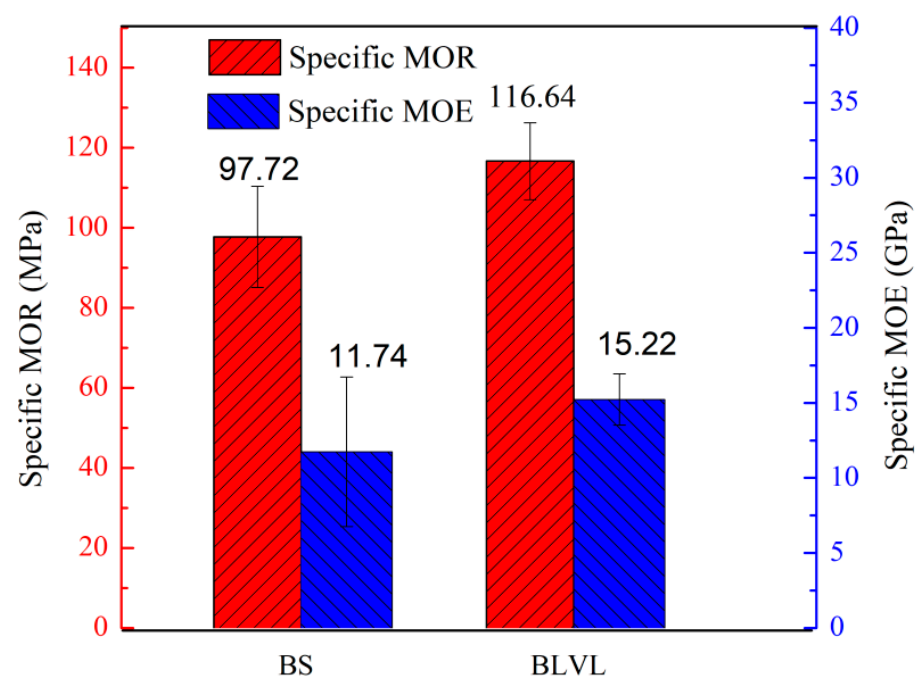

Figure 11. Specific MOR and specific MOE of BS and BLVL.

\section{Discussion and Conclusions}

The innovation of utilizing whole bamboo bundle veneers prepared via the weaving method provides an efficient and convenient way for industry to develop applications for bamboo bundle veneers. The light transmittance and mechanical stiffness were used as indicators to evaluate the uniformity of the physical and mechanical properties of the bamboo veneers, where the density and mechanical stiffness of the entire bamboo bundle veneers could be observed in a nondestructive manner. The evaluation method of the veneer units was an effective basis that will promote the industrial production of low-density and high-uniformity bamboo bundle veneers. The brooming, glueing, and heat treatment of the bundles were varied to analyze their effects on the resulting veneers.

The number of broomings and dippings had a significant effect on the light transmittance and mechanical stiffness of the bamboo bundle veneers. The heat treatment had a greater effect on the mechanical stiffness and little effect on the light transmittance. Bamboo bundle veneers with two broomings had a lower light transmittance and better uniformity.

The use of bamboo bundle veneers to make BLVL can effectively improve the physical and mechanical properties of BLVL, while these improvements to the processing of bamboo bundle veneers can help improve the efficiency of BLVL production. The uniformity of the density and mechanical properties of BLVL produced from the bamboo bundle veneers were superior to those of BS with 
hybrid paving. The investigation of the whole process and quality evaluation of the bamboo bundle veneers provided a reference for the preparation and performance prediction of high-performance, low-density, bamboo-bundle-structure engineered materials.

Author Contributions: Conceptualization, F.C. and G.W.; Methodology, F.C.; Software, H.Z. and X.W.; Validation, F.C., G.W. and H.Z.; Formal analysis and investigation, H.Z.; Resources, F.C.; Data curation, H.Z.; Writing-original draft preparation, H.Z.; Writing-review and editing, H.Z. and L.M.S.; Supervision, F.C.; Project administration and funding acquisition, G.W.

Funding: This research was funded by the Serial Key Manufacturing Technology of Bamboo Bundle Laminated Composite Structural Materials for Prefabricated Buildings Program, 1632019003.

Acknowledgments: The technical guidance from International Centre for Bamboo and Rattan is gratefully acknowledged. The authors would also like to thank Fujian Youzhu Technology Co., Ltd. for supplying the raw materials.

Conflicts of Interest: The authors declare no conflict of interest.

\section{References}

1. Yu, Y.; Zhu, R.; Wu, B.; Yu, A.; Hu, W. Fabrication, material properties, and application of bamboo scrimber. Wood Sci. Technol. 2015, 49, 83-98. [CrossRef]

2. Yu, Y.; Huang, X.; Yu, W. A novel process to improve yield and mechanical performance of bamboo fiber reinforced composite via mechanical treatments. Compos. Part B 2014, 54, 48-53. [CrossRef]

3. Muhammad, A.; Rahman, M.R.; Hamdan, S.; Sanaullah, K. Recent developments in bamboo fiber-based composites: A review. Polym. Bull. 2019, 76, 2655-2682. [CrossRef]

4. Sharma, B.; Gatóo, A.; Bock, M.; Ramage, M. Engineered bamboo for structural applications. Constr. Build. Mater. 2015, 81, 66-73. [CrossRef]

5. Wei, Y.; Ji, X.; Duan, M.; Li, G. Flexural performance of bamboo scrimber beams strengthened with fiber-reinforced polymer. Constr. Build. Mater. 2017, 142, 66-82. [CrossRef]

6. Yu, Y.; Liu, B.; Yu, W. Research progress on new technology and new product development of bamboo scrimber. Int. Wood Ind. 2014, 7, 8-13.

7. He, S.; Xu, J.; Wu, Z.; Yu, H.; Chen, Y.; Song, J. Effect of bamboo bundle knitting on enhancing properties of bamboo scrimber. Eur. J. Wood Wood Prod. 2018, 76, 1071-1078. [CrossRef]

8. Kumar, A.; Vlach, T.; Laiblova, L.; Hrouda, M.; Kasal, B.; Tywoniak, J. Engineered bamboo scrimber: Influence of density on the mechanical and water absorption properties. Constr. Build. Mater. 2016, 127, 815-827. [CrossRef]

9. Li, H.; Chen, F.; Xian, Y.; Deng, J.; Wang, G.; Cheng, H. An empirical model for predicting the mechanical properties degradation of bamboo bundle laminated veneer lumber (blvl) by hygrothermal aging treatment. Eur. J. Wood Wood Prod. 2017, 75, 553-560. [CrossRef]

10. Chen, F.; Jiang, Z.; Wang, G.; Li, H.; Simth, L.M.; Shi, S.Q. The bending properties of bamboo bundle laminated veneer lumber (blvl) double beams. Constr. Build. Mater. 2016, 119, 145-151. [CrossRef]

11. Wang, G.; Chen, F. Development of bamboo fiber-based composites. Adv. High Strength Nat. Fibre Compos. Constr. 2017, 235-255. [CrossRef]

12. Yu, Z. Processing Technology of Laminated Bamboo-Bundle Veneer Lumber and Its Application Performance. Ph.D. Thesis, Chinese Academy of Sciences, Beijing, China, 2012.

13. Zhang, D.; Ren, W.; Chen, F.; Deng, J.; Wang, G. Effect of Surface Veneer Joint on Properties of Bamboo Bundle Laminated Veneer Lumber. J. For. Res. 2014, 42, 83-85.

14. Yu, Y.; Liu, R.; Huang, Y.; Meng, F.; Yu, W. Preparation, physical, mechanical, and interfacial morphological properties of engineered bamboo scrimber. Constr. Build. Mater. 2017, 157, 1032-1039. [CrossRef]

15. Shangguan, W. Effects of heat treatment on the properties of bamboo scrimber. J. Wood. Sci. 2016, 62, 1-9. [CrossRef]

16. Zhu, Y.; Mo, X.; Gu, D.; Guan, M. Preparation and performance evaluation of bamboo bundles. For. J. Eng. 2007, 21, 41-43.

17. Wu, B.; Yu, Y.; Qi, J.; Yu, W. Effects of bamboo bundles treated with fine fluffing and carbonized trentment on the properties of bamboo scrimber. J. Nanjing For. Univ. (Nat. Sci. Ed.). 2014, 38, 115-120. 
18. Qi, J.; Xie, J.; Yu, W.; Chen, S. Effects of characteristic inhomogeneity of bamboo culm nodes on mechanical properties of bamboo fiber reinforced composite. J. For. Res. 2015, 26, 1057-1060. [CrossRef]

19. Lee, C.H.; Yang, T.H.; Cheng, Y.W.; Lee, C.J. Effects of thermal modification on the surface and chemical properties of moso bamboo. Constr. Build. Mater. 2018, 178, 59-71. [CrossRef]

20. Li, T.; Cheng, D.; Walinder, M.; Zhou, D. Wettability of oil heat-treated bamboo and bonding strength of laminated bamboo board. Ind. Crop. Prod. 2015, 69, 15-20. [CrossRef]

21. Kwon, J.H.; Shin, R.H.; Ayrilmis, N.; Han, T.H. Properties of solid wood and laminated wood lumber manufactured by cold pressing and heat treatment. Mater. Des. 2014, 62, 375-381. [CrossRef]

22. Xu, M.; Cui, Z.; Chen, Z.; Xiang, J. Experimental study on compressive and tensile properties of a bamboo scrimber at elevated temperatures. Constr. Build. Mater. 2017, 151, 732-741. [CrossRef]

23. Qin, L.; Yu, W.; Yu, Y. Research on properties of reconstituted bamboo lumber made by thermo-treated bamboo bundle curtains. For. Prod. J. 2012, 62, 545-550. [CrossRef]

24. Nugroho, N.; Ando, N. Development of structural composite products made from bamboo I: Fundamental properties of bamboo zephyr board. J. Wood. Sci. 2000, 46, 68-74. [CrossRef]

25. Nugroho, N.; Ando, N. Development of structural composite products made from bamboo II: Fundamental properties of laminated bamboo lumber. J. Wood. Sci. 2001, 47, 237-242. [CrossRef]

26. Rao, W. Research of the Wood-bamboo Composite Scrimber. Master's Thesis, Nanjing Forestry University, Nanjing, China, 2003. (In Chinese).

27. Gu, D. The Key Process and Property Research of Wood-Bamboo Scrimber. Master's Thesis, Nanjing Forestry University, Nanjing, China, 2008. (In Chinese).

28. Chung, M.J.; Wang, S.Y. Mechanical properties of oriented bamboo scrimber boards made of Phyllostachys pubescens (moso bamboo) from Taiwan and China as a function of density. Holzforschung 2018, 72, 151-158.

29. Möller, R.; Mild, G. Protection of Moso bamboo (Phyllostachys pubescens) materials against fungal decay and discolouration by treatment with wood preservatives. Eur. J. Wood Wood Prod. 2019, 77, 139-145.

30. Hakkou, M.; Pétrissans, M.; Zoulalian, A.; Gérardin, P. Investigation of wood wettability changes during heat treatment on the basis of chemical analysis. Polym. Degrad. Stab. 2015, 89, 1-5. [CrossRef]

31. Windeisen, E.; Strobel, C.; Wegener, G. Chemical changes during the production of thermo-treated beech wood. Wood Sci. Technol. 2007, 41, 523-536. [CrossRef]

32. Yildiz, S.; Tomak, E.D.; Yildiz, U.C.; Ustaomer, D. Effect of artificial weathering on the properties of heat treated wood. Polym. Degrad. Stab. 2013, 98, 1419-1427. [CrossRef] 